This item was submitted to Loughborough's Research Repository by the author.

Items in Figshare are protected by copyright, with all rights reserved, unless otherwise indicated.

\title{
Millionaire investors: financial advisors, attribution theory and gender differences
}

PLEASE CITE THE PUBLISHED VERSION

PUBLISHER

Taylor \& Francis

VERSION

AM (Accepted Manuscript)

PUBLISHER STATEMENT

This is an Accepted Manuscript of an article published by Taylor \& Francis in The European Journal of Finance on 21 February 2018, available online: http://www.tandfonline.com/10.1080/1351847X.2018.1438301.

LICENCE

CC BY-NC-ND 4.0

\section{REPOSITORY RECORD}

Baeckström, Ylva, Joanne Silvester, and Rachel A. J. Pownall. 2019. "Millionaire Investors: Financial Advisors, Attribution Theory and Gender Differences". figshare. https://hdl.handle.net/2134/9864182.v1. 


\title{
Millionaire Investors: Financial Advisors, Attribution Theory and Gender Differences
}

Ylva Baeckström*, Jo Silvester ${ }^{\dagger}$, Rachel A. J. Pownall ${ }^{\ddagger}$

\begin{abstract}
To date little attention has been paid to how social cognitive bias can influence how financial advisors interpret and respond to the needs of millionaire investors, and if this varies depending on the gender of the investor. This research investigates whether experienced professional financial advisors who work with millionaire investors make different attributions for the control and knowledge that investors have of their investments, and if they make different investment portfolio recommendations to equivalent male and female investors. Using methodology novel to finance, this vignette-based study that controls for gender finds evidence that professional financial advisors judge millionaire female investors to have less control over their investment portfolios relative to men. Empirical results also show that female advisors judge women to be less knowledgeable about investments than men. Despite such perceptual differences, advisors recommend equally risky portfolios to male and female investors. These results have implications for wealth management institutions and the monitoring of financial advisors for millionaire individuals.
\end{abstract}

JEL Classification: G11, G12.

Keywords: Portfolio Choice; Investment Decisions; Financial Advice; Risk-Taking; Gender.

\footnotetext{
* Cass Business School, City, University of London, UK \& TIAS School for Business and Society, Tilburg University. The Netherlands Email: ylva.baeckstrom.1@cass.city.ac.uk

${ }^{\dagger}$ University of Exeter Business School, University of Exeter, UK. Email: J.Silvester4@exeter.ac.uk

* Maastricht University and TIAS School for Business and Society, Tilburg University, The Netherlands. Email r.pownall@maastrichtuniversity.nl
} 


\section{Introduction}

A growing literature in behavioural finance shows that investors rely on their own perceptions and intuitive beliefs when making investment decisions, rather than selecting efficient portfolios that optimally balance risk and reward (Benartzi and Thaler 2001; Kahneman 2003). However, a large proportion of millionaires do not make investment decisions themselves, but rely instead on advice provided by financial advisors. As such, these investment decisions also depend on the judgements that advisors make about the needs and preferences of their clients (i.e., the investors). To date, very little research has considered how advisors judge the needs of their clients, or indeed the role that social cognition plays in the way that advisors make sense of their clients' needs. More specifically, there has been little consideration of how social cognitive bias may differentially impact how advisors interpret and make sense of the needs and preferences of different groups (e.g., male and female investors), and how this in turn influences advisors' portfolio recommendations.

This paper addresses this notable lacuna in existing research by drawing on attribution theory from social psychology (Harvey et al. 2014), and by utilising vignette methodology to investigate whether practising professional financial advisors explain and respond to the needs and preferences of male and female millionaire investors differently. Vignettes, (i.e., penportraits of fictional millionaire investors), are used to ascertain the judgements that advisors make aboutthe investment knowledge, control and risk tolerance of potential clients. This methodology, which is frequently used in social psychology yet novel to finance, is effective in extracting attitudes and judgements in quantitative research (Schoenberg and Ravdal 2000). In this study, the vignettes allow for a clean experiment where each of the ten vignettes explicitly defines a client and provides the same information to advisors who rate the vignettes.

By introducing attribution theory to behavioural finance, and asking financial advisors working with millionaire investors to complete an innovative vignette based survey, it is 
possible to investigate whether advisors judge the needs of male and female fictional millionaire investors, with the same characteristics and circumstances, in the same manner or whether they exhibit a bias. The study tests the hypotheses that social cognitive bias leads experienced advisors who work with millionaire investors to (a) perceive female investors as having less knowledge and control over their investments than men, and (b) to recommend comparatively less risky investment portfolios to women.

The study makes several contributions to the behavioural finance literature. Firstly, it draws on attribution theory to provide a basis for predicting and studying the potential for social cognitive bias in interpersonal decision-making. While this theory has received extensive study in other fields of psychology and social judgement, it has yet to be fully explored in the context of financial advice. Secondly, the research design introduces a new and innovative methodology (i.e., vignettes), which provides a tried and tested method to investigate gender and other group differences in the way that financial advisors support and advise clients. Thirdly, the study investigates the judgements of individuals who work as financial advisors and have many years of experience advising millionaire clients. As such it extends existing research beyond laboratory based studies and considers the judgements of experts rather than novices. Finally, the research is important because it focuses on a specific need, namely the importance of providing appropriate and valid advice to millionaire female investors, a group that is growing significantly in size, yet for whom advice is often perceived as unsatisfactory (Friedland 2013).

\subsection{Millionaire Investors}

According to the World Wealth Report (2013), high net worth, or 'millionaire' investors are defined as individuals who hold at least US\$1million, or the equivalent, in financial or investable assets. Millionaires play an important investment role in the global economy. For example, in the UK, millionaires own $46 \%$ of the household wealth, and the UK 
has the third highest number of millionaires globally (Credit Suisse 2016). In 2015, when the data for this study were collected, 961,000 UK households had assets worth over US\$1m excluding property and luxury goods; a $12.4 \%$ increase from the previous year (Boston Consulting Group 2016). There are also approximately 40 financial institutions in the UK that provide support for these individuals and manage in excess of US\$50 million each (A.T. Kearney 2013).

Among the wealthy, female wealth growth has outpaced that of men. The Telegraph reported that women aged between 22-29 years are earning more than men (Fraser 2015), and by 2020 it is predicted that women will make up 53\% of all UK millionaires (Centre for Economics and Business Research 2013). Women's economic empowerment therefore represents a major social change (The Economist December 30, 2009). Yet, despite this apparent financial success, there is evidence that women remain disadvantaged relative to men in terms of their investments. For example, while women have a longer life expectancy than men (83 compared to 79 years: World Health Organization 2016), they are less likely than men to have a pension plan (Hung and Yoong 2010), and those women who do have a pension plan have built up a smaller amount typically due to a higher prevalence of part-time work and taking time out for family care. Moreover, women have been shown to have a lower allocation to risky assets in their retirement savings (Sundén and Surette 1998). Interestingly there is also evidence from recent studies that indicates women are more likely to be dissatisfied with their financial advisors compared to men, and typically perceive financial advising to be a male orientated activity (Friedland 2013). These findings have prompted many investment organisations to question what more they can do to better understand and support the needs of wealthy women, and ultimately to attract and retain this important client group.

However, one area that has received relatively little attention from finance researchers to date, concerns the way in which advisors interpret and explain client needs, and how this 
can be influenced by unconscious stereotypical assumptions or group bias. For example, studies investigating social cognition in other work contexts have found that people are routinely and often unconsciously biased in the way they perceive others, including making different causal judgments about the needs and behaviour of men and women (Deaux and Major 1987; Feather and Simon 1975). This study builds on existing work by drawing on attribution theory to investigate whether financial advisors interpret the needs of equivalent male and female millionaire investors differently, and whether these differences affect the portfolio recommendations they make.

\section{Background on Advising Investors: Attribution Theory}

By introducing cognitive psychology to the traditional rational agent model, Tversky and Kahneman (1986) demonstrated robust and consistent evidence of irrational decision making behaviour among investors previously unexplained by traditional rational economic theory. They argued that the rational economic theory had been "conceived as a normative model of an idealised decision maker, not as a description of the behaviour of real people" (Tversky and Kahneman 1986, 251). In doing so attention shifted to the subjective and sometimes irrational biases that influence decisions. Behavioural finance researchers have been particularly interested in the impact of psychological bias on investor decision-making (Muradoglu and Harvey 2012) and how different biases illustrate errors that investors make as they allow irrational behaviour into their decision making process. Kahneman (2003) describes these as emotional brain filters that allow emotions to manipulate decision making. Loewenstein et al. (2001) suggest that risk attitudes are emotional expressions, rather than rational evaluations, with situational complexity and uncertainty likely to increase the influence of emotions (Forgas 1995).

While behavioural finance adds complexity to traditional models that explain optimal, but not actual, decision making behaviour (Nofsinger 2005), its focus has tended to remain on 
decisions about investments rather than decisions about investors. For example, studies have explored the influence of self-attribution bias on investor decisions; researchers have shown that individuals are consistently more likely to attribute positive outcomes (e.g., successful investment) to self and negative outcomes (e.g., unsuccessful investment) to external causes, making it difficult for investors to learn from their mistakes (Hoffmann and Post 2014) and improve their investment outcomes. Mittal (2010) found evidence that investors differ in the extent to which they demonstrate this self-attribution bias, and that investors showing high levels of bias are more likely to believe that they have both superior knowledge relative to others and a belief that they can outperform the market (Barber and Odean 1999). Those investors who are prone to the self-attribution bias have a tendency to realise gains too quickly and to hold on to underperforming investments (Feng and Seasholes 2005). Overconfident investors also attach importance to past return experiences to reinforce their convictions (Hoffmann and Post 2016) leading them to trade too much, generating higher transaction costs and ultimately lower returns (Hoffmann and Post 2016; Odean 1999).

As yet very little behavioural finance research has considered interpersonal attributional bias in situations where one individual (i.e., a professional financial advisor) gives investment advice to another (i.e., a client). These situations require the advisor to interpret the client's needs, and to make a recommendation about how he or she should invest their wealth on the basis of these interpretations. In these situations, interpersonal and inter-group attributional bias have been shown to influence the way in which observers interpret and respond to the behaviour and needs of others (Kelley 1973; Martinko and Thomason 1998).

\subsection{Delegated Portfolio Management}

Unlike self-managed wealth, wealth managed through financial advisors involves joint decision making within an agency relationship. This is defined by Ross $(1973,134)$ as a 
"relationship... between two (or more) parties when one, designated as the agent, acts for, on behalf of, or as representative for the other, in a particular domain of decision problems".

In this study, the principal (i.e., the investor) delegates some decision making authority to the agent (Jensen and Meckling 1976) by appointing them as their investment portfolio advisor responsible for providing them with information and investment advice (Bhattacharya and Peiderer 1985). In the UK, the activities of financial advisors are regulated by the Financial Conduct Authority (FCA) in order to protect investors and ensure fair treatment. Importantly, in situations where investors engage a professional financial advisor, investment decisions are not made in isolation, but rather in conversation with the advisor. He or she can then influence the decision making process by providing information and advice about different investment possibilities, depending on their understanding of the investor's need. .

Yet, like investors, professional advisors can be vulnerable to cognitive bias (De Bondt 1998; Chalmers and Reuter 2010; Karabulut 2011) and may also fail to correct the biases an investor may have (Mullainathan, Noeth and Schoar 2012). It is therefore possible that advisors' judgements about clients, and any recommendations they make, will be influenced by the stereotypes and assumptions they have about investors' needs, based on investor characteristics such as gender.

\subsection{Gender differences}

Gender differences are of particular interest to wealth management institutions and regulators due to the rapid growth in female wealth and the resultant economic impact of investment decisions made by women. Differences in the investment behaviour between men and women are well documented. Previous research has found that women invest less, trade less frequently and select lower risk investments in their portfolios, and with a smaller allocation into risky assets, it is argued that women are more risk averse Charness and Gneezy (2012) and Koedijk, Pownall, and Statman (2015). Studies show that women also tend to 
perceive themselves as less confident in making investment decisions (Estes and Hosseini 1988; Barber and Odean 2001), and are generally and historically less financially literate than men (Campbell 2006; Lusardi and Mitchell 2007). Dwyer, Gilkeson and List (2002) find that this lower financial literacy translates into women making lower risk investment decisions. Agnew et al. (2008) report a similar link between lower financial literacy, confidence and increased risk aversion, with $38 \%$ of women in their study opting for a less risky annuity retirement option compared to $29 \%$ of men. These findings provide further support for Sundén and Surette's (1998) assertion that women make less risky retirement asset allocation choices than men.

However, extant research has generally focused on identifying differences between the preferences and styles of male and female investors, with women typically perceiving themselves to be less knowledgeable about investing, less confident when making investment decisions and more likely to demonstrate a lower risk tolerance which translates into a desire for lower risk investments decisions compared to men (Barber and Odean 2001, 2002; Croson and Gneezy 2009; Hira and Loibl 2008). Yet to date there has been no attempt to investigate whether such differences might arise because women receive different investment advice based on advisors' assumptions about their risk tolerance. For example, while many wealthy women engage professional advisors to guide them through the investment decision making process, less is known about whether the risk tolerance of female and male investors is perceived differently by professional financial advisors.

Evidence that such differences may exist can be found in research concerned with attribution theory, which considers the everyday causal explanations that people make both for their own behaviours and the behaviour of others (Harvey et al. 2014; Heider 1958; Weiner 1985; Wong and Weiner 1981), which in turn influence future decisions and actions (Fincham and Jaspars 1979; Martinko and Thomason 1998). Attribution theorists have studied the impact 
that perceptions, biases and stereotypes have on behaviour, particularly in relation to their impact on differential decision-making for men and women (Silvester and Koczwara 2012). For example, in work psychology, attributional rationalisation is the tendency for managers to attribute successful performance by women to unstable and circumstantial causes (e.g., effort and luck) and equivalent male performance to internal and stable causes (e.g., ability) as a result of in-group/out-group bias (Heilman, Block, and Martell 1995; Swim and Sanna 1996). There is now considerable evidence that observers make different judgements depending on the gender of the observed, with female success more typically attributed to luck (Deaux and Emswiller 1974; Feather and Simon 1975). In the workplace, Silvester and Koczwara (2012) found that senior managers attributed the success of female junior managers to more external and temporary causes like the actions of others, while they attributed success on the part of junior male managers to more internal controllable and stable causes like talent and ability. In general, observers tend to judge men to have more control or confidence over their actions than women (Weiner et al. 1971).

To date, however, no research has considered this bias in the context of investment advice; nor to whether it might lead advisors to perceive the needs of wealthy male and female investors differently, and thus to provision of different types of investment advice. Yet circumstantial evidence exists to support this proposition, for example, a study of undergraduate students by Daruvala (2007) found that both male and female observers, (i.e., the students in the sample), judged women to be more risk-averse than men. Likewise, in a study conducted in the financial services industry, Wang (1994) found that brokers providing investment advice to individuals with US\$25,000 to invest, allocated less time and recommended less risky investments to women relative to men.

The existence of biased social perception is likely to be particularly important for wealthy investors who rely on advisors who make investment recommendations on their 
behalf. Yet, existing research focuses on how professional advisors are prone to behavioural biases when making investment decisions, rather than whether the perception that advisors have of different investors is biased. Moreover, the few studies that do consider advisors' perceptions look at their how they perceive affluent investors (Wang 1994) or students (Daruvala 2007), and not millionaire investors. Therefore, investigating the judgements that advisors make about wealthy female and male investors provides an important addition to current understanding of potential gender differences in the way investment recommendations are made.

By drawing on attribution theory to examine the assertion that gender differences in investor preference may be in part perceptual and influenced by advisor bias, the present study makes four contributions to existing knowledge. First, it explores differences in the attributions made by financial advisors for male and female investors and the impact these may have on investment recommendations. Secondly, the study utilises a novel methodology, namely a vignette survey that enables attributions for male and female investors to be elicited in a controlled and standardised way. Thirdly, it introduces the new demographic of millionaire investors, a 'hard to reach' group rarely considered in previous studies. Fourthly, the study obtains ratings from experienced financial advisors whose clients are predominantly millionaires.

\subsection{Hypotheses}

Drawing on behavioural finance research that finds that female investors tend to rate themselves as less knowledgeable, less confident and more risk averse relative to male investors, and attribution research which finds differences in the way that the behaviour of men and women is explained by others, this study tests whether a similar bias may apply to how financial advisors perceive the relative knowledge, control and risk tolerance of male and 
female millionaire investors. We hypothesise that, in situations where all other characteristics and investment circumstances are held equal:

Hypothesis 1: Financial advisors will rate female millionaire investors to be less knowledgeable about investments than male millionaire investors.

Hypothesis 2: Financial advisors will perceive female millionaire investors to have less control over their investments than male millionaire investors.

Hypothesis 3: Financial advisors will allocate lower risk portfolios to female millionaire investors relative to male millionaire investors.

\section{Methodology}

\subsection{Context and Participants}

This study introduces new methodology into behavioural finance through the use of vignettes to elicit attributions from financial advisors about male and female millionaire investors under controlled conditions. The vignette experiment was conducted in the UK private banking sector. The UK is of particular interest due to its high proportion of millionaire investors and its prominence globally in the wealth management sector. This sector continues to grow, both in terms of total wealth under management, and specifically the growth in female wealth. Additionally, changes in the regulatory environment following the credit crisis has increased the focus that the Financial Conduct Authority (FCA) places on advisors' behaviour towards their clients, adding to the study's face validity.

Data were collected directly from financial advisors, employed by private banks and other wealth management firms in the UK, who are working with millionaire individual investors (i.e., those with more than US\$1 million or equivalent to invest). This unique data set was accessible due to the first researcher's extensive insight into the sector obtained through nearly twenty years of working in the industry. In the UK advisors are regulated by the FCA through their employer. The FCA requires that all advisors undertake investment and portfolio 
construction qualifications to ensure they understand how to risk profile investors, and are therefore able to recommend suitable investment portfolios with an asset allocation appropriate to each risk profile. This training also ensures that, before providing any advice, an advisor must first establish which investments are suitable for a particular client using pre-designed investment questionnaires. These questionnaires are designed to meet regulatory requirements by evidencing suitable investment recommendations for clients (Estrada 2016); categorising investors' risk profiles using information about their personal circumstances, such as age, amount of wealth, source of wealth, goals, marital status, dependents, expenditure, profession, investment experience. Although risk profiles may vary depending on the institution, they typically range from 1 (risk averse) to 5 (aggressive), with each rating associated with a recommended target asset allocation or investment portfolio. For example, institutions may create model investment portfolios for each level of investor risk classification depending on the investor's personal characteristics which set the boundary as to which investments are suitable for each investor. Although the FCA does not determine the metrics used by institutions it overseas the suitability process for assessing the risk investors are prepared to take (Financial Services Authority 2011) ${ }^{4}$.

Although individual advisors are responsible for providing suitable investment advice, they can also influence this initial determination of the client's risk profile, thereby adding further opportunity for subjectivity. Importantly, advisors' judgements of investors are critical for determining what investments can be offered. The industry and the financial regulator expect that advisors rationally follow these sorts of metrics, but as yet relatively little attention has been paid to the possibility that advisors are influenced by other client characteristics, like gender, that ought not to affect portfolio recommendations.

\subsection{Development of Vignette Questionnaire}

\footnotetext{
${ }^{4}$ The Financial Services Authority underwent a name change to the Financial Conduct Authority in April 2013.
} 
This study utilises a vignette based questionnaire to collect ratings for hypothetical millionaire investors that respondents might typically encounter in their work. Although vignette methodology has a long history in psychological and sociological research, it is not common in the finance literature. Atzmüller and Steiner (2010: 128) define a vignette as "a short, carefully constructed description of a person, object, or situation, representing a systematic combination of characteristics". Vignettes are often used as part of a questionnaire in order to allow researchers to capture ratings for standardised scenarios from multiple respondents. By asking questions on decision-making following a brief hypothetical scenario, vignette methodology combines a traditional survey with an experiment and is particularly suited to eliciting attitudes and judgements in quantitative research (Schoenberg and Ravdal 2000).

In this study ten vignettes were developed; each was approximately 100 words in length and described a different fictional millionaire investor. Care was given to making sure that the narratives were realistic, and that each vignette included sufficient detail and contextual factors to ensure face validity, verified by professional financial advisors consulted during the development phase. For example, every vignette contained information about the investor that an advisor might expect to know soon after being introduced to a new client and would enable them to make judgements about their investment needs. The same categories of variables were included in each vignette (e.g., age, profession, wealth), but varied to increase the credibility and range of likely investors.

In order to compare the effects of investor gender, two versions of each vignette were created: one where the investor was male and one where they were female. Thus, gender was allowed to vary while keeping all other details constant. Table 1 shows examples of two vignettes illustrating the changes made for male and female versions. For example, the first vignette in Table 1 is a 36 year old IT consultant with $£ 800,000$ in liquid wealth and a property 
portfolio. Half of the respondents will rate this vignette as Susan (i.e., a woman) and half the respondents as Michael (i.e., a man). The second vignette portrays another fictional client, namely a 59 year old CEO called Nick or Anna. The methodology enables advisors to rate different types of fictional clients in a clean experiment where only gender is altered.

\section{INSERT TABLE 1 ABOUT HERE}

In order to ensure that both a female and a male version of each vignette were rated, two versions of the survey (i.e., survey A and survey B) were created. In both versions the vignettes are presented in the same order, but in version A, even-numbered vignettes describe male investors and odd numbered vignettes describe female investors, while in version B evennumbered vignettes are female and odd-numbered vignettes are male. This approach follows the methodology pioneered by Schein (1976, Schein et al. 1996), and allows the gender of the hypothetical millionaire client in each vignette to vary, while controlling for other individual and situational factors.

After reading each vignette, study participants were asked to respond to three questions: firstly, 'On a scale from 1-10 how knowledgeable would you rate this client to be about investments?' (where 1 = not at all knowledgeable, 10 = extremely knowledgeable), secondly 'Relative to the average investor, how much control do you think this client is likely to have over their investments?' (where $1=$ a lot less than the average investor and $5=$ a lot more than the average investor).

Thirdly, respondents were presented with seven investment portfolios that varied according to risk and asked: 'Which of the following portfolios would you recommend to this client?' In order to enable a controlled measure of risk, seven investment portfolios were constructed using varied asset allocations, to reflect differing levels of risk ranging from 1 (very low) to 7 (very high). This approach is consistent with Modern Portfolio Theory (MPT), where 
investors select a portfolio that balances likely risk and reward (Wilford 2012), and follows methodology used in previous research by De Bondt (1998) and Karabulut (2010). Each portfolio includes a mix of investments, including stocks, bonds and other assets (Marston 2011). Table 2 shows the asset allocation of the seven portfolios.

\section{INSERT TABLE 2 ABOUT HERE}

In each of the seven portfolios the asset mix is varied to represent different risk, and asset volatility is measured by the standard deviation of the return distribution of the portfolios. For example, Portfolio 1 contains 51\% bonds and 19\% equities, while Portfolio 7 contains 3\% bonds and $86 \%$ equities. Portfolio 1 has the lowest risk (as measured by the standard deviation of the empirical distribution) and portfolio seven the highest risk, with a gradual increase in the ratio of risky assets (1) to higher-risk assets (7). These portfolios mirror the standard approach taken to match investor risk tolerance by allocating them to one of five or more risk profiles, and matching them with suitable portfolios with varied asset allocation. The asset allocation in the portfolios is derived from the FTSE Wealth Management Association Private Investor Indices (portfolios), regarded as benchmark portfolios for the wealth management industry in the UK and thus familiar to advisors (The Wealth Management Association 2015). Finally, biographical questions were included in the questionnaire, asking respondents to indicate their gender, age and the number of years they had worked as a financial advisor.

The questionnaire was piloted with three financial advisors and three investment specialists, who each provided feedback on the vignettes, questions, and the portfolio composition. This process ensured that the questions were easy to understand, and that the advisors were able to correctly infer that portfolio risk increased incrementally between portfolios 1 to 7, without the standard deviation being disclosed to respondents. It also provided confirmation that the vignettes were believable and realistic (Rahman 1996) in their depiction 
of credible millionaire clients (Finch 1987). Feedback provided during piloting resulted in minor amendments to some questions and vignettes. The amended questionnaire was further tested with ten advisors who completed it online, resulting in a few additional minor changes to language.

\subsection{Procedure}

The online questionnaire was distributed randomly to over 400 professional financial advisors, whose responses were recorded anonymously. Consent was also sought from respondents to use their anonymised data as part of an academic study about investment advice provision that would be published. Distribution occurred in two ways. First, a major UK private bank agreed to disseminate the questionnaire to all investment advisors in their UK offices who were working with millionaire UK clients. Participants were invited to take part in the research by a senior director, and reassured that all information would be treated in confidence such that respondents would be anonymous to the researchers and their employer. This generated a total of 50 respondents ( 46 male and 4 female, mean age 37.9 years and mean experience 9.0 years). As this institution employs approximately 200 investment advisors, the sample represented about $25 \%$ of the population. Secondly, a snowball sampling methodology was utilised to secure respondents from over ten additional financial institutions. This involved emailing financial advisors who were known to the researchers and working with millionaire clients. These individuals were invited both to complete the questionnaire and to distribute the online questionnaire to other colleagues in similar roles. Again, all information was provided anonymously. This methodology generated 79 respondents from ten UK institutions (56 male and 23 female, mean age 44.2 years and mean experience 14.3 years). Respondent ages ranged from 25 to 59 years for the first sample (A) and 27 to 67 for the second sample (B). Despite slight differences between the two samples, a decision was taken to treat them as a single data set for the purposes of analysis, given that the age range and experience of respondents in both 
samples were broadly similar, and the target group for respondents (i.e., financial advisors working with millionaire investors) is an exceptionally hard-to-reach group.

Although 151 respondents began the survey, respondents who had not rated more than one vignette were deemed to be not randomly missing, and therefore excluded from the analysis (Newman 2014). A total of 129 respondents were included in the analysis, yielding 1147 observations in total (64 respondents completed survey A and 65 completed survey B). The full sample of respondents reported in Table 3 is very similar to the demographics of the financial advisor population as a whole reported by Hannon (2014): 79.1\% of advisors in the sample are male, they have a mean age of 41.74 years and an average of 12.78 years of experience advising wealthy clients.

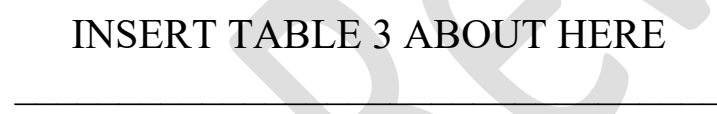

\section{Results}

In order to analyse differences between the way in which advisors perceive equivalent female and male investors, and how this translates into portfolio recommendations, our identification strategy using vignettes with gender as a treatment effect results in a simple approach of testing difference in means. Means were calculated and two-tailed t-tests were used to compare responses for knowledge rating (H1), perceived control (H2) and recommended risk portfolio (H3). The analysis included responses from 129 participants who rated the ten vignettes. Taking account of missing data this yielded a total of 1147 observations included in the analysis. Means of ratings were computed for the overall responses per vignette and then split into the gender of the vignette. Significance is reported using P values. Additional analysis calculating means and ratings based on the gender of the advisor are also considered.

The results for the full sample are presented with the summary results in table 4 below. The overall mean computations show that advisors are on average in agreement with how 
knowledgeable the investors in the vignettes are and the portfolios that they recommend. However, means show that male and female vignettes are judged to have different levels of control over their investments. Male vignettes are attributed an average rating of 3.27 whereas female vignettes were rated to have less control $(\mathrm{M}=3.08)$, which is significant at the $1 \%$ level. The results for each rating are presented in more detail below.

\section{INSERT TABLE 4 ABOUT HERE}

Result 1: The results for knowledge ratings (H1) are presented in more detail in table 5. Our analysis does not find evidence that advisors perceive women to be significantly less knowledgeable than men $(M=5.76$ for male vignettes and $M=5.61$ for female vignettes $)$, therefore we reject Hypothesis 1: 'Financial advisors will rate female millionaires less knowledgeable about investments than male investors who are millionaires'. Additional t-test analysis reveals that female respondents rate millionaires in male vignettes to be more knowledgeable $(M=5.60)$ than they do millionaires in female vignettes $(M=5.22)$, which is significant at the $5 \%$ level.

\section{INSERT TABLE 5 ABOUT HERE}

Result 2: The control ratings yield significant differences. Overall advisors rated female millionaires as having less control over their investments relative to males $(\mathrm{M}=3.27$ for male vignettes and $\mathrm{M}=3.08$ for female vignettes. Therefore we fail to reject Hypothesis 2: 'Financial advisors will perceive female millionaires to have less control over their investments than male investors who are millionaires'. Additional analysis taking advisor gender into account shows that, overall, the lowest control ratings were made by female respondents for female millionaires $(\mathrm{M}=2.96)$, whereas female respondents rated male millionaires to have 
the highest control over their investments $(\mathrm{M}=3.27)$, significant at the $5 \%$ level. Also male advisors attribute lower control to female millionaires $(M=3.11)$ versus male millionaires $(M=3.27)$, significant at the 5\% level (see table 6).

\section{INSERT TABLE 6 ABOUT HERE}

Result 3: T-tests revealed that when all advisors were considered together there was no significant difference in the type of portfolios they recommended to male and female millionaires (female investors $M=3.91$, male investors $M=3.96$ ). Thus hypothesis 3 : 'Financial advisors will allocate lower risk portfolios to female millionaires relative to male investors who are millionaires', was also rejected. However, inspection of the data reveals that the lowest risk portfolios are recommended to female investors by female advisors $(M=3.67)$, relative to male investors $(\mathrm{M}=3.97)$; this difference is significant at the $10 \%$ level. Conversely the highest risk portfolios are more likely to be recommended to male millionaires by male advisors $(M=3.99)$ and female advisors $(M=3.97)$. The results for the recommended portfolio ratings are summarised in table 7.

\section{INSERT TABLE 7 ABOUT HERE}

To analyse more carefully where in the distribution these differences between gender occur, conditional densities are drawn which condition on the gender of the financial advisor. These follow the non-parametric technique proposed by Racine and Li (2004), which applies a kernel method of density estimation to discrete variables. Density functions that show the differences in the degree of knowledge, control as well as the recommended portfolios are 
shown in figures $1-3$. Although there is a slight shift to the left for all three variables for female advisors, it is not significant at the $95 \%$ level.

\section{INSERT FIGURES 1, 2 AND 3 ABOUT HERE}

\section{Discussion}

The rapid increase in the number of women millionaires in the UK, means that the way in which these women invest their wealth is of social and economic interest. It is also of particular interest to wealth management institutions that wish to attract and support female clients, and to institutional regulators of financial advice provided to individual investors. Although behavioural finance theorists demonstrate how individual investors use their own intuitive beliefs and apply biases when making investment decisions for themselves (Kahneman 2003; Benartzi and Thaler 2001), much less attention has been given to whether financial advisors who aid millionaire investors may display similar biases when judging the needs and providing investment advice for male and female clients. Consequently, there is a need to explore how advisors understand and respond to the needs of male and female millionaire investors.

By introducing a novel vignette based methodology to finance this study draws on attribution theory to explore if advisors perceive investors differently due to their gender, whilst holding all other variables constant. Based on previous findings in the literature about differences between male and female investors, and previous attribution theory research, the expectation was that advisors would judge female vignettes (millionaire investors) to be less knowledgeable, to have less control over their investments, and to recommend lower risk portfolios to female relative to male vignettes. This study found that advisors did not rate the investment knowledge of men and women differently, but that women millionaires were perceived to have less control over their investments. 
Contrary to the hypotheses, the results also show that advisors did not recommend lower risk portfolios to investors in the female compared to male vignettes. The perceived control findings in this study are in line with attribution research that has found that both male and female observers attribute female success to less controllable causes (Silvester and Koczwara 2012), and judge men as likely to have more control or confidence over their actions (Weiner et al. 1971). Investors who are judged to have less control over their investments might also be perceived to be more reliant on their advisors, and more likely to seek investment advice (Guiso and Japelli 2006; Karabulut 2010; Bluethgen, et al. 2008). Agnew et al. (2008), for example, report a link between self-perceived low financial literacy, confidence and lower risk aversion, results which were expected to be replicated when testing for the perception that advisors have of investors in this study. However, results from the present study do not provide evidence of differences in the social perception that advisors have regarding the financial literacy of men and women, instead they demonstrate that advisors recommend portfolios with the same allocation to risky assets to equivalent male and female investors despite judging women to have less control over their investments.

Yet, when controlling for gender of advisor, the results show that both the knowledge that advisors perceive investors in the vignettes to have and the portfolios that they recommend are significantly altered. Relative to male advisors, female advisors judge female vignettes to have less investment knowledge, but they also recommend less risky portfolios to female investors than to male investors. The control rating was also significantly lower for female investors when controlling for the gender of both advisors and investors.

Whilst it may be problematic to generalise with a sample of 129 advisors from ten UK wealth management institutions (Berk 1983), it is particularly difficult for researchers to access the community of advisors for millionaire investors. Indeed, the response rate for this voluntary survey was $38 \%$, which is similar to the average of $35.7 \%$ cited by Baruch and Holtom (2008), 
suggesting a good level of engagement despite the absence of financial compensation. Likewise, as there are only forty UK institutions that individually manage over US\$50 million (A.T. Kearney 2013), the sample is broadly representative of the wider population. Due to the anonymity of the survey data, information about the characteristics of non-respondents was not available for comparative analysis (Viswesvaran, Barrick, and Ones 1993). While it is possible that this sample is not an exact representation of the advisory industry, and may be subject to sample selection bias (Berk 1983), we argue that it has high external validity due to its broad representation of a unique target population. Thus, while ratings were provided by respondents who were recruited in two different ways, splitting the sample into two subgroups for analysis purposes would have substantially reduced the sample size with effects on significance (Wheatley and Hills 2001) and hence the credibility of any subgroup effects (Sun et al. 2002). Similarly, while the proportion of women respondents in the total sample resembles that found in the advisory market as a whole (i.e., 21\% female advisors: Hannon 2014), sample A had only $8 \%$ female respondents. Advisors in sample A were also slightly younger and less experienced than those in sample B. Consequently, it was not possible with this data to explore meaningful sub-group differences.

That said, the findings presented in this paper suggest that the gender of an advisor may be influential in investment recommendations, with the lowest mean ratings for knowledge, control and portfolio recommendation all given by female advisors for female vignettes. Interestingly, the highest ratings on these measures are provided by male respondents for male vignettes. These findings deserve further exploration in future research.

Previous research has also found that an observer's own risk tolerance may influence the risk rating they make for another person (Daruvala 2007). Therefore, future studies might examine whether female advisors are less risk tolerant than their male peers, and thus more prone to recommend lower risk investments. Similarly, the level of self-rated knowledge of an 
advisor might influence the level of knowledge they attribute to others. However, it may also be the case that female advisors are simply more accurate in interpreting the extent to which their clients feel knowledgeable, confident, and averse to risk.

According to classical theory we would not have expected a significant difference between the male and female investors. Yet based on previous findings of self-perceived lower financial literacy, confidence and risk tolerance among women, we expected that the judgements or social perception that advisors make of male and female investors would follow a similar pattern. The data source and findings presented in this paper provide unique new insights into advising millionaire individuals in a study with high face validity. Although varied, the results illustrate that advisors interpret the needs of female millionaire investors differently to male investors, and that the gender of the advisor significantly contributes to differences in that judgement. Although advisors exhibited less bias than expected, they judge female investors to have significantly less control over their investments. Such findings highlight the complex and subjective nature of how the needs of male and female millionaires are understood. Financial markets regulators, and the institutions that the advisors work for, may trust that advisors follow metrics, yet it seems that attributional bias may also contribute to the investment advice received by male and female investors; with the gender of the professional who provides the investment advice an important consideration.

\subsection{Practical Implications}

This study has significant implications as it addresses one of the problems faced by the wealth management industry: how to attract and encourage wealthy female clients to invest their wealth. A recent report shows that only $25 \%$ of affluent women in the US have an advisor, and of this group 67\% feel their advisor misunderstands their needs (Hewlett and Moffitt 2014). Moreover, women are generally less satisfied with their advisors, and more likely to perceive financial advising as a male orientated activity (Friedland 2013). Yet, despite significant 
growth in female wealth, women are less likely than men to have retirement savings (Hung and Yoong 2010) and less likely to have a high allocation to risky assets (Sundén and Surette 1998), which means that with a longer life expectancy than men, women risk outliving their savings. Consistently lower risk investment portfolio recommendations to female investors result in underinvestment relative to both the market and their peers and a likelihood of lower riskadjusted returns.

It may of course also be problematic that the advisors in this study perceive women to be equally knowledgeable to men and to have less control over their investments but still recommend equally risky portfolios to women. This has potential consequences for the financial industry with regards to savings and retirement portfolios, and increases the scope for more tailored investment advice. These findings may also be of interest to financial regulators in relation to consideration of the fair treatment of consumers regardless of their gender, and the need to raise awareness among advisors of the effect that psychological heuristics can have on financial decision-making.

\subsection{Theoretical Implications}

Through introducing attribution theory to the finance field, the concept that social perceptions matter when investors make investment decisions jointly with an investment advisor, contributes to extant behavioural finance research. Such attributions and social perceptions that advisors make of millionaire investors are elicited through the employment of novel vignette based methodology with results that underpin previous findings in attribution theory where both male and female observers perceive female millionaire investors to have less control over their investments. Attribution theory can therefore help to inform and expand existing behavioural finance theory by showing that social perception also matters when financial advisors judge the needs of millionaire investors, potentially influencing the investment advice provided and ultimately how the wealth is invested. Additionally, this study 
illustrates how the finance literature can benefit from the application of vignette methodology to elicit judgements in controlled experiments.

\subsection{Limitations and Future Research Directions}

There are several interesting areas for future research. The study can be replicated for less wealthy investors to explore if perceptions are different for another demographic. Future research could also consider geographical differences. Although out of scope in the current study, exploration of the correlation between advisor's own risk tolerance and the risk perception of investors could add further insight and inform the findings presented in this paper. Increased understanding of other biases which result from agency conflicts, caused by mismatches between the agent's and the principal's own self-interests would also be beneficial. Such potential conflicts are important and may lead to advisors recommending riskier portfolios that attract higher incentives for the advisor. Additionally, millionaire investors may have several dedicated financial advisors, a complexity not considered in this study. Other studies might consider this as well as the depth and length of the relationship between the advisor and the investor. To advance knowledge about the interaction between financial advisors and investors future researchers may consider how the judgements that advisors make of investors match the expectation of investors. Perhaps a relative over-reliance by female investors on advisors means that advisors have a higher level of influence over the investments they recommend to female investors which might in turn affect the allocation to risky assets, and a possible conflict of interest. One might argue for lower risk portfolios to investors who display a higher level of dependence and lower level of confidence. Since this study concerns the study of judgements made by very experienced advisors, it may well be that this experience contributes to perceptual differences as experience, is negatively correlated with biases (Feng and Seasholes, 2005). Millionaires might also be judged differently than those who are less 
wealthy and advisors might attribute a higher risk tolerance to millionaires who can absorb a higher level of risk relative to those with less in investable wealth.

\section{Conclusion}

By introducing attribution theory to behavioural finance through the employment of an innovative vignette based study this paper examined whether advisors alter their judgment of the needs of millionaire investors depending on the client's gender. With all other variables held constant, advisors were asked to rate the investment knowledge and the control that investors have over their investments, and to recommend one of seven investment portfolios with varied asset allocation (risk) to ten pen portraits (vignettes) of male and female investors. The study tested whether previous research findings, which indicate that female investors are less knowledgeable, less confident and less risk tolerant relative to male investors, hold in how millionaire investors are perceived by advisors. The results found that both male and female advisors rated female investors as having less control over their investments than male investors suggesting that women millionaires may be perceived as less confident and more reliant on advice by their investment advisors. However, advisors make the same judgements about the investment knowledge of men and women and make equally risky portfolio recommendations regardless of the gender of the investor. The findings add to extant behavioural finance literature in relation to the potential for bias and gender differences in client relationships by considering the impact of social cognition (i.e., attribution theory) on the perceptions of investment advisors providing advice to millionaire investors.

\section{References}

Agnew, Julie R., Lisa R. Anderson, Jeffrey R. Gerlach, and Lisa R. Szykman. 2008. "Who Chooses Annuities? An Experimental Investigation of the Role of Gender, Framing, and Defaults.” In American Economic Review, 98:418-22. doi:10.1257/aer.98.2.418.

Atzmüller, Christiane, and Peter M. Steiner. 2010. "Experimental Vignette Studies in Survey Research." Methodology: European Journal of Research Methods for the Behavioral and Social Sciences. doi:10.1027/1614-2241/a000014. 
A.T. Kearney. 2013. "Wealth Management in the United Kingdom: Survival of the Fittest." Accessed 13 May

2017.https://www.atkearney.co.uk/documents/872085/1584567/Wealth+Management+i $\mathrm{n}+$ the+United+Kingdom+-+Survival+of+the+Fittest.pdf/679aa41e-6d83-49b7-80a4a942e96275fb.

Barber, Brad M., and Terrance Odean. 2002. "Online Investors: Do the Slow Die First?" Review of Financial Studies 15 (2): 455-87. doi:10.2139/ssrn.219242.

Barber, Brad M, and Terrance Odean. 2001. "Boys Will Be Boys: Gender, Overconfidence, and Common Stock Investment." Quarterly Journal of Economics 116 (1): 261-92. doi:10.1162/003355301556400.

Barber, Brad M., and Terrance Odean. 1999. "The Courage of Misguided Convictions." Financial Analysts Journal. doi:10.2469/faj.v55.n6.2313.

Baruch, Y. and B.C. Holtom, 2008. "Survey response rate levels and trends in organizational research.” Human Relations, 61(8), pp.1139-1160.

Benartzi, Shlomo, and Richard H. Thaler. 2001. "Naive Diversification Strategies in Defined Contribution Saving Plans." American Economic Review 91 (1): 79-98. doi:10.1257/aer.91.1.79.

Berk, Richard A. 1983. “An Introduction to Sample Selection Bias in Sociological Data." American Sociological Review 48 (3): 386. doi:10.2307/2095230.

Bhattacharya, Sudipto, and Paul Pfleiderer. 1985. "Delegated Portfolio Management." Journal of Economic Theory 36 (1): 1-25. doi:10.1016/0022-0531(85)90076-6.

Bluethgen, Ralph, Andreas Gintschel, Andreas Hackethal, and Armin Müller. 2008. "Financial Advice and Individual Investors' Portfolios." Business. doi:10.2139/ssrn.968197.

Boston Consulting Group. 2015. "A million British households are now millionaires - even excluding their houses" The Telegraph, June 7. Accessed 25 September 2015. http://www.telegraph.co.uk/business/2016/06/07/a-million-british-households-are-nowmillionaires--even-excludin/.

Campbell, Anne. 2006. "Sex Differences in Direct Aggression: What Are the Psychological Mediators?” Aggression and Violent Behavior. doi:10.1016/j.avb.2005.09.002.

Centre for Economics and Business Research. 2006. "Female millionaires set to rise". $B B C$, August 13. http://news.bbc.co.uk/1/hi/business/4788815.stm.

Chalmers, John, and Jonathan Reuter. 2010. "What Is the Impact of Financial Advisors on Retirement Portfolio Choices and Outcomes ?" National Bureau of Economic Research, 1-31. doi:10.3386/w18158. 
Charness, Gary, and Uri Gneezy. 2012. "Strong Evidence for Gender Differences in Investment." Journal of Economic Behavior \& Organization 83 (1): 50-58. doi: $10.2139 /$ ssrn.648735.

Credit Suisse Global Wealth Databook James Davies, Rodrigo Lluberas and Anthony Shorrocks, 2016. Accessed: 2nd June 2017. https://www.credit-suisse.com/uk/en/aboutus/research/research-institute/news-and-videos/articles/news-andexpertise/2016/12/en/the-global-wealth-pyramid-2016.html.

Croson, Rachel, and Uri Gneezy. 2009. "Gender Differences in Preferences." Journal of Economic Literature. doi:10.1257/jel.47.2.448.

Daruvala, Dinky. 2007. "Gender, Risk and Stereotypes." Journal of Risk and Uncertainty 35: 265-83. doi:10.1007/s11166-007-9024-7.

De Bondt, Werner F.M. 1998. “A Portrait of the Individual Investor.” European Economic Review. doi:10.1016/S0014-2921(98)00009-9.

Deaux, Kay, and Tim Emswiller. 1974. "Explanations of Successful Performance on SexLinked Tasks: What Is Skill for the Male Is Luck for the Female." Journal of Personality and Social Psychology 29 (1): 80-85. doi:10.1037/h0035733.

Deaux, Kay, and Brenda Major. 1987. "Putting Gender into Context: An Interactive Model of Gender-Related Behavior.” Psychological Review 94 (3): 369-89. doi:10.1037/0033295X.94.3.369.

Dwyer, Peggy D., James H. Gilkeson, and John A. List. 2002. "Gender Differences in Revealed Risk Taking: Evidence from Mutual Fund Investors.” Economics Letters 76 (2): 151-58. doi:10.1016/S0165-1765(02)00045-9.

Estes, Ralph, and Jinoos Hosseini. 1988. "The Gender Gap on Wall Street: An Empirical Analysis of Confidence in Investment Decision Making." Journal of Psychology 122: 577-90.

Estrada, Javier. 2016. “GHAUS asset allocation.” Journal of Asset Management, 17(1), pp. 19.

Feather, N T, and J G Simon. 1975. "Reactions to Male and Female Success and Failure in Sex-Linked Occupations: Impressions of Personality, Causal Attributions, and Perceived Likelihood of Different Consequences." Journal of Personality and Social Psychology 31 (1): 20-31. doi:10.1037/h0076240.

Feng, Lei, and Mark S. Seasholes. 2005. "Do Investor Sophistication and Trading Experience Eliminate Behavioral Biases in Financial Markets?" Review of Finance. doi:10.1007/s10679-005-2262-0.

Financial Services Authority. 2011. "Assessing suitability: Establishing the risk a customer is willing and able to take and making a suitable investment selection." Accessed 25 May 2016. https://www.fca.org.uk/publication/finalised-guidance/fsa-fg11-05.pdf. 
Finch, Janet. 1987. “The Vignette Technique in Survey Research.” Sociology 21 (1): 105-14. doi:10.1177/0038038587021001008.

Fincham, F., and J. Jaspars. 1979. "Attribution of Responsibility to the Self and Other in Children and Adults." Journal of Personality and Social Psychology 37 (9): 1589-1602. doi:10.1037/0022-3514.37.9.1589.

Fraser, I. (2015) Women earn more than men in their 20s - until the pay gap hits at age 30 . The Telegraph. 28 August. Accessed 3 September 2016. http://www.telegraph.co.uk/women/womens-business/11832042/Women-earn-morethan-men-in-their-20s-until-the-pay-gap-hits-at-age-30.html.

Friedland Lilli. 2013. “The Women's Economy Has Arrived.” Accessed 30 April 2014. http://www.fwreport.com//article.php?id=56777\#.WCTa7OGLTVo.

FTSE Wealth Management Association. 2015. "WMA Private Investor Indices.” Accessed 21 March 2015 http://www.thewma.co.uk/private-investor-indices/.

Guiso, Luigi, and Tullio Jappelli. 2006. "Information Acquisition and Portfolio Performance. CSEF Working Paper, Center for Studies in Economics and Finance. Accessed 13 June 2016. http://econpapers.repec.org/paper/sefcsefwp/167.htm.

Hannon, Kerry, 2014. Where Are All The Female Financial Advisers?. 8 May. Accessed 25 May 2017. https://www.forbes.com/sites/nextavenue/2014/05/08/where-are-all-thefemale-financial-advisors/\#19fc3772d813.

Harvey, Paul, Kristen Madison, Mark Martinko, T Russell Crook, and Tamara A Crook. 2014. "Attribution Theory in the Organizational Sciences: The Road Traveled and the Path Ahead." The Academy of Management Perspectives 28: 128-46. doi:10.5465/amp.2012.0175.

Heider Fritz, VS Folkes, Susan Koletsky, JL Graham, S. J. Sherman, C. C. Presson, L. Chassin, et al. 1958. "The Psychology of Interpersonal Relations." The Journal of Marketing 56: 322. doi:10.1037//0022-3514.46.1.57.

Heilman, Madeline E., Caryn J. Block, and Richard F. Martell. 1995. "Sex Stereotypes: Do They Influence Perceptions of Managers?" Journal of Social Behavior and Personality 10 (6): 237-52.

Hewlett Sylvia A., and Andrea T. Moffitt. 2014. "Harnessing the Power of the Purse: Female Investors and Global Opportunities for Growth." Center for Talent Innovation.

Hira, Tahira K., and Cäzilia Loibl. 2008. "Gender Differences in Investment Behavior.” In Handbook of Consumer Finance Research, 253-70. doi:10.1007/978-0-387-757346_15.

Hoffmann, Arvid O.I., and Thomas Post. 2014. "Self-Attribution Bias in Consumer Financial Decision-Making: How Investment Returns Affect Individuals' Belief in Skill." Journal of Behavioral and Experimental Economics 52: 23-28. doi:10.1016/j.socec.2014.05.005. 
Hoffmann, Arvid O.I., and Thomas Post. 2016. "How Does Investor Confidence Lead to Trading? Linking Investor Return Experiences, Confidence, and Investment Beliefs." Journal of Behavioral and Experimental Finance 12: 65-78. doi:10.1016/j.jbef.2016.09.003.

Hung, Angela, and Joanne Yoong. 2010. "Asking for Help: Survey and Experimental Evidence on Financial Advice and Behavior Change." SSRN Electronic Journal. doi:10.2139/ssrn.1532993.

Jensen, Michael C, and William H Meckling. 1976. "Theory of the Firm : Managerial Behavior, Agency Costs and Ownership Structure" Journal of Financial Economics 3: 305-60. doi:http://dx.doi.org/10.1016/0304-405X(76)90026-X.

Kahneman, Daniel. 2003. "Maps of Bounded Rationality: Psychology for Behavioral Economics." The American Economic Review 93: 1449-75. doi: $10.1257 / 000282803322655392$.

Karabulut, Yigitcan. 2010. "Financial Advice: An Improvement for Worse?” Unpublished Working Paper 49 (January): 33. doi:10.2967/jnumed.114.142042.

Kelley, Harold H. 1973. "The Processes of Causal Attribution.” American Psychologist. doi: $10.1037 / \mathrm{h} 0034225$.

Koedijk, Kees G, Rachel A. J. Pownall and Meir Statman. 2015. "Aspirations for Income: Status, competitiveness and risk attitudes. Unpublished Manuscript.

Loewenstein, G F, E U Weber, C K Hsee, and N Welch. 2001. "Risk as Feelings." Psychological Bulletin 127: 267-86. doi:10.1037/0033-2909.127.2.267.

Lusardi, Annamaria, and Olivia S. Mitchell. 2007. "Baby Boomer Retirement Security: The Roles of Planning, Financial Literacy, and Housing Wealth." Journal of Monetary Economics 54 (1): 205-24. doi:10.1016/j.jmoneco.2006.12.001.

Markowitz, Harry. 1952. "Portfolio Selection." The Journal of Finance 7 (1): 77-91. doi:10.2307/2975974.

Marston, R. C. 2011. Front Matter, in Portfolio Design: A Modern Approach to Asset Allocation. John Wiley \& Sons, Inc: Hoboken. NJ. USA. doi: 10.1002/9781118267660.

Martinko, Mark J., and Neal F. Thomson. 1998. "A Synthesis and Extension of the Weiner and Kelley Attribution Models." Basic and Applied Social Psychology 20 (4): 271-84. doi:10.1207/s15324834basp2004.

Mittal, Manish. 2010. "Study of Differences in Behavioral Biases in Investment DecisionMaking Between the Salaried and Business Class Investors." IUP Journal of Behavioral Finance 7 (4): 20-34.

http://search.proquest.com/docview/1212700118?accountid=79789. 
Mullainathan, Sendhil, Markus Noeth, and Antoinette Schoar. 2012. "The Market for Financial Advice: An Audit Study.” NBER Working Paper Series, 1-32. doi:10.3386/w17929.

Muradoglu, Gulnur, and Nigel Harvey. 2012. "Behavioural Finance: The Role of Psychological Factors in Financial Decisions." Review of Behavioral Finance 4 (2): 6880. doi:10.1108/19405971211284862.

Newman, Daniel. A. 2014. "Missing Data: Five Practical Guidelines." Organizational Research Methods 17 (4): 372-411. doi:10.1177/1094428114548590.

Nofsinger, John. R. 2005. The Psychology of investing. The Prentice Hall series in finance. $2^{\text {nd }}$ ed.

Odean, Terrance. 1999. “Do Investors Trade Too Much?” American Economic Review. doi:10.1257/aer.89.5.1279.

Racine, Jeff, and Li Qi. 2004. "Nonparametric estimation of regression functions with both categorical and continuous data." Journal of Econometrics 119 (1): 99-130.

Ross, Stephen A. 1973. "The Economic Theory of Agency: The Principal's Problem.” The American Economic Review 63: 134-39. doi:10.2307/1817064.

Schein, Virginia, Ruediger Müller, Terri Lituchy, and Jiang Liu. 1996. "Think Managerthink Male: A Global Phenomenon?" Journal of Organizational Behavior 17 (1): 33-41. doi:10.1002/(SICI)1099-1379(199601)17:1<33::AID-JOB778>3.3.CO;2-6.

Schein, Virginia. 1976. “Think manager-think male.” Atlanta Economic Review. 26: 21-24.

Schoenberg, Nancy E., and Hege Ravdal. 2000. "Using Vignettes in Awareness and Attitudinal Research." International Journal of Social Research Methodology. doi:10.1080/136455700294932.

Silvester, Jo, and Anna Koczwara. 2012. "Explaining male and female leadership potential: New York and London." Paper presented at the Society for Industrial \& Organizational Psychology Annual Conference. San Diego, US.

Sundén, Annika E, and Brian J Surette. 1998. "Gender Differences in the Allocation of Assets in Retirement Savings Plans." American Economic Review 88: 207-11. $\mathrm{http}: / /$ search.ebscohost.com/login.aspx?direct=true \&db=bth\&AN=665315\&site=ehostlive\&scope $=$ site.

Swim, Janet K, and Lawrence J Sanna. 1996. "He's Skilled, She's Lucky: A Meta-Analysis of Observers' Attributions for Women's and Men's Successes and Failures.” Personality and Social Psychology Bulletin 22 (5): 507-19. doi:10.1177/0146167296225008.

The Economist. 2009 "Female Power". 30 December. Accessed 30 March 2014. http://www.economist.com/node/15174418.

The World Health Organization. 2016. http://apps.who.int/gho/data/node.main.688. 
The World Wealth Report. 2013. Accessed 13 Jan 2016.

https://www.worldwealthreport.com/. Accessed 14 November 2014.

Tversky, Amos, and Daniel Kahneman. 1986. "Rational Choice and the Framing of Decisions.” The Journal of Business. doi:10.1086/296365.

Viswesvaran, Chockalingam, Murray R Barrick, and Deniz S Ones. 1993. "How Definitive Are Conclusions Based on Survey Data: Estimating Robustness To Nonresponse." Personnel Psychology 46 (3): 551-67. doi:10.1111/j.1744-6570.1993.tb00884.x.

Wang, Penelope. 1994. "Brokers still treat men better than women". Money (Chicago, Ill.) 23 (6): 108-110. doi:0149-4953.

Weiner, Bernard. 1985. "An Attributional Theory of Achievement Motivation and Emotion." Psychological Review 92 (4): 548-73. doi:10.1037/0033-295X.92.4.548.

Weiner, Bernard, Irene Frieze, Andy Kukla, and Robert M. Rosenbaum. 1971. "Perceiving the Causes of Success and Failure." Developmental Psychology 11 (1): 103. doi: $10.1037 / \mathrm{h} 0076132$.

Wheatley, K and Hills, R. K. (2001). "Inappropriate reporting and interpretation of subgroups in the AML-BFM 93 study". https://www.ncbi.nlm.nih.gov/labs/articles/11681429/.

Wilford, D. Sykes. 2012. "True Markowitz or Assumptions We Break and Why It Matters." Review of Financial Economics 21: 93-101. doi:10.1016/j.rfe.2012.06.003.

Wong, Paul T., and Bernard Weiner. 1981. "When People Ask 'why' questions, and the Heuristics of Attributional Search." Journal of Personality and Social Psychology 40 (4): 650-63. doi:10.1037/0022-3514.40.4.650. 
(1) Susan (Michael), a 36-year old IT consultant, has done well in the London property boom. She $(\mathrm{He})$ has generated liquid wealth of $£ 800,000$ in addition to a property portfolio worth $£ 1.8$ million net of mortgages. The portfolio generates about $£ 105,000$ bringing her (his) total yearly income to $£ 180,000$. Together with her (his) long-term partner she (he) is expecting a baby in 3 months. It is her (his) dream to resign from her (his) boring job in 5 years to look after her (his) family. Her (his) partner has got bond and stock investments, but Susan (Michael) has always focused on property. However, she (he) realises that she (he) ought to diversify and is prepared to commit an initial $£ 500,000$. Susan (Michael) loves to travel and may buy a property abroad in the future.

(2) Nick (Anna), 59, is the CEO of a FTSE250 company. You are aware that he (she) has about $£ 1.5$ million exposure to the company stock through incentive schemes. He (She) is paid $£ 580,000$ including bonuses per year, of which he (she) only spends half. It is very hard to get time in his (her) diary but he (she) is polite and forthcoming when you meet. He (She) has expressed an interest in bonds and asks you what alternative investments are. He (She) confesses to having panic-sold his (her) portfolio and lost a lot of money during the credit crisis. Nick (Anna) would like to hedge his (her) single stock exposure and invest an initial $£ 1$ million of his (her) $£ 2.5$ million savings. He (She) is married and his (her) twins will be graduating from University this year. His (Her) wife (husband) would like him (her) to retire at 62 so that they can move to the Caribbean.

Notes: gender of the client in each vignette was varied as shown in ( ). 
Table 2. Portfolio asset allocation composition

\begin{tabular}{cccccccc}
\hline Asset class & $\begin{array}{c}\text { Portf 1 } \\
(\%)\end{array}$ & $\begin{array}{c}\text { Portf 2 } \\
(\%)\end{array}$ & $\begin{array}{c}\text { Portf 3 } \\
(\%)\end{array}$ & $\begin{array}{c}\text { Portf 4 } \\
(\%)\end{array}$ & $\begin{array}{c}\text { Portf 5 } \\
(\%)\end{array}$ & $\begin{array}{c}\text { Portf 6 } \\
(\%)\end{array}$ & $\begin{array}{c}\text { Portf 7 } \\
(\%)\end{array}$ \\
\hline UK Equities & 11 & 19 & 27 & 35 & 37 & 40 & 42 \\
International Equities & 8 & 11 & 14 & 18 & 28 & 38 & 44 \\
Bonds & 51 & 45 & 39 & 32 & 20 & 7 & 3 \\
Cash & 6 & 5 & 5 & 5 & 4 & 2 & 0 \\
Commercial Property & 6 & 5 & 5 & 5 & 5 & 5 & 3 \\
Alternatives / Hedge funds & 18 & 15 & 10 & 5 & 6 & 8 & 8 \\
Total & 100 & 100 & 100 & 100 & 100 & 100 & 100 \\
& & & & & & & \\
\hline
\end{tabular}

Note: asset allocation of Portfolios $1-7=$ Portf. 
Table 3. Descriptives for respondents

\begin{tabular}{lccc}
\hline & & & \\
\hline Respondents & $\mathrm{N}$ & Age & Experience \\
\hline Full Sample & & & \\
All & 129 & 41.74 & 12.78 \\
Male & 102 & 41.14 & 12.42 \\
Female & 27 & 44 & 14.15 \\
& & & \\
Sample A & & & \\
All & 50 & 37.86 & 9.00 \\
Male & 46 & 38.04 & 10.70 \\
Female & 4 & 35.75 & 7.40 \\
& & & \\
Sample B & & & \\
All & 79 & 44.19 & 14.27 \\
Male & 56 & 43.68 & 13.84 \\
Female & 23 & 45.43 & 15.30 \\
& & & \\
\hline
\end{tabular}

Notes: Table 3 summarises the respondents used in the analysis.

Initially the full sample, followed by separation of Samples A \& B

Number of respondents, mean age and years' experience. 
Table 4. Summary results for vignette ratings by all respondents.

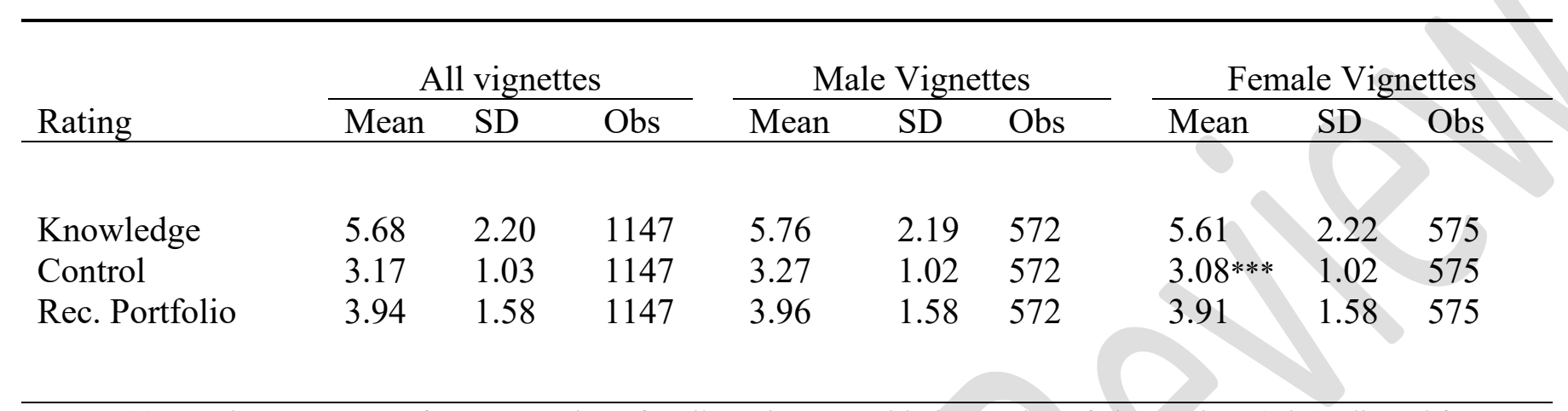

Notes: (1) Based on responses of 129 respondents for all 10 vignettes with the number of observations (Obs) adjusted for missing data. $* * *$ Significant at $1 \%$ level. 
Table 5. Knowledge ratings by gender of advisor and gender of vignette.

\begin{tabular}{|c|c|c|c|c|c|c|c|c|c|}
\hline \multirow{2}{*}{$\begin{array}{l}\text { Knowledge } \\
\text { Rating }\end{array}$} & \multicolumn{3}{|c|}{ All Respondents } & \multicolumn{3}{|c|}{ Male Respondents } & \multicolumn{3}{|c|}{ Female Respondents } \\
\hline & Mean & SD & Obs & Mean & SD & Obs & Mean & SD & Obs \\
\hline All Vignettes & 5.68 & 2.20 & 1147 & 5.75 & 2.14 & 919 & 5.41 & 2.41 & 228 \\
\hline Male Vignettes & 5.76 & 2.19 & 572 & 5.79 & 2.16 & 458 & 5.60 & 2.30 & 114 \\
\hline Female Vignettes & 5.61 & 2.22 & 575 & 5.71 & 2.12 & 461 & $5.22 * *$ & 2.52 & 114 \\
\hline
\end{tabular}

Notes: Shows the differences for the knowledge rating controlling for the gender of both the vignettes and the respondents. Observations $=$ Obs. ${ }^{* *}$ Significance at $5 \%$ level. 
Table 6. Control ratings for vignettes by gender of advisor and gender of vignette.

\begin{tabular}{|c|c|c|c|c|c|c|c|c|}
\hline \multirow[b]{2}{*}{ Control Rating } & \multicolumn{3}{|c|}{ All Respondents } & \multicolumn{3}{|c|}{ Male Respondents } & \multicolumn{2}{|c|}{ Female Respondents } \\
\hline & Mean & SD & Obs & Mean & $\mathrm{SD}$ & Obs & Mean $\quad$ SD & Obs \\
\hline All Vignettes & 3.17 & 1.03 & 1147 & 3.19 & 1.00 & 919 & 3.12 & 228 \\
\hline Male Vignettes & 3.27 & 1.02 & 572 & 3.27 & 1.02 & 458 & $\begin{array}{ll}3.27 & 1.05\end{array}$ & 114 \\
\hline Female Vignettes & $3.08^{* * *}$ & 1.0227 & 575 & $3.11 * *$ & 0.99 & 461 & $2.96^{* *} \quad 1.16$ & 114 \\
\hline
\end{tabular}

Notes: Shows the differences for the control rating controlling for the gender of both the vignettes and the respondents. Observations $=$ Obs. *** Significant at $1 \%$ level. ** Significant at $5 \%$ level. 
Table 7. Recommended portfolio rating by gender of advisor and gender of vignette.

\begin{tabular}{|c|c|c|c|c|c|c|c|c|}
\hline \multirow[b]{2}{*}{ Portfolio Rating } & \multicolumn{3}{|c|}{ All Respondents } & \multicolumn{3}{|c|}{ Male Respondents } & \multicolumn{2}{|c|}{ Female Respondents } \\
\hline & Mean & SD & Obs & Mean & $\mathrm{SD}$ & Obs & Mean & $\mathrm{SD} \quad \mathrm{Obs}$ \\
\hline All Vignettes & 3.94 & 1.58 & 1147 & 3.98 & 1.58 & 919 & 3.75 & 1.56 \\
\hline Male Vignettes & 3.96 & 1.58 & 572 & 3.99 & 1.60 & 458 & 3.84 & 1.49 \\
\hline Female Vignettes & 3.91 & 1.58 & 575 & 3.97 & 1.56 & 461 & $3.67 *$ & $1.63 \bigcirc 114$ \\
\hline
\end{tabular}

Notes: Shows the differences for the recommended portfolio rating controlling for the gender of both the vignettes and the respondents. Observations $=$ Obs. $(3) *$ Significant at $10 \%$ level. 
Figure 1. Conditional Density Function: Knowledge.

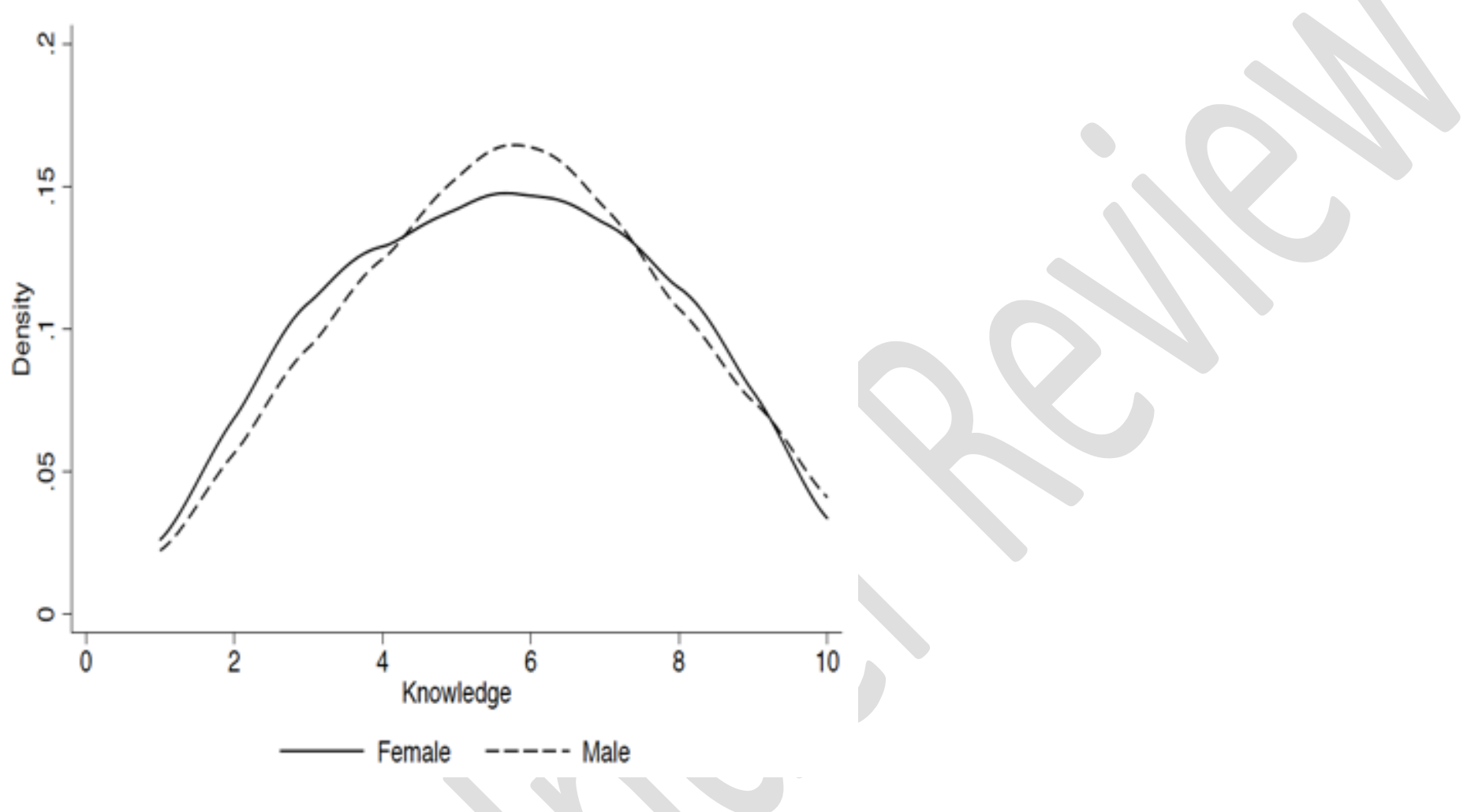

Notes: The density graph shows the difference in the distribution of the degree of knowledge, conditioning on gender of the financial advisors. 
Figure 2. Conditional Density Function: Control.

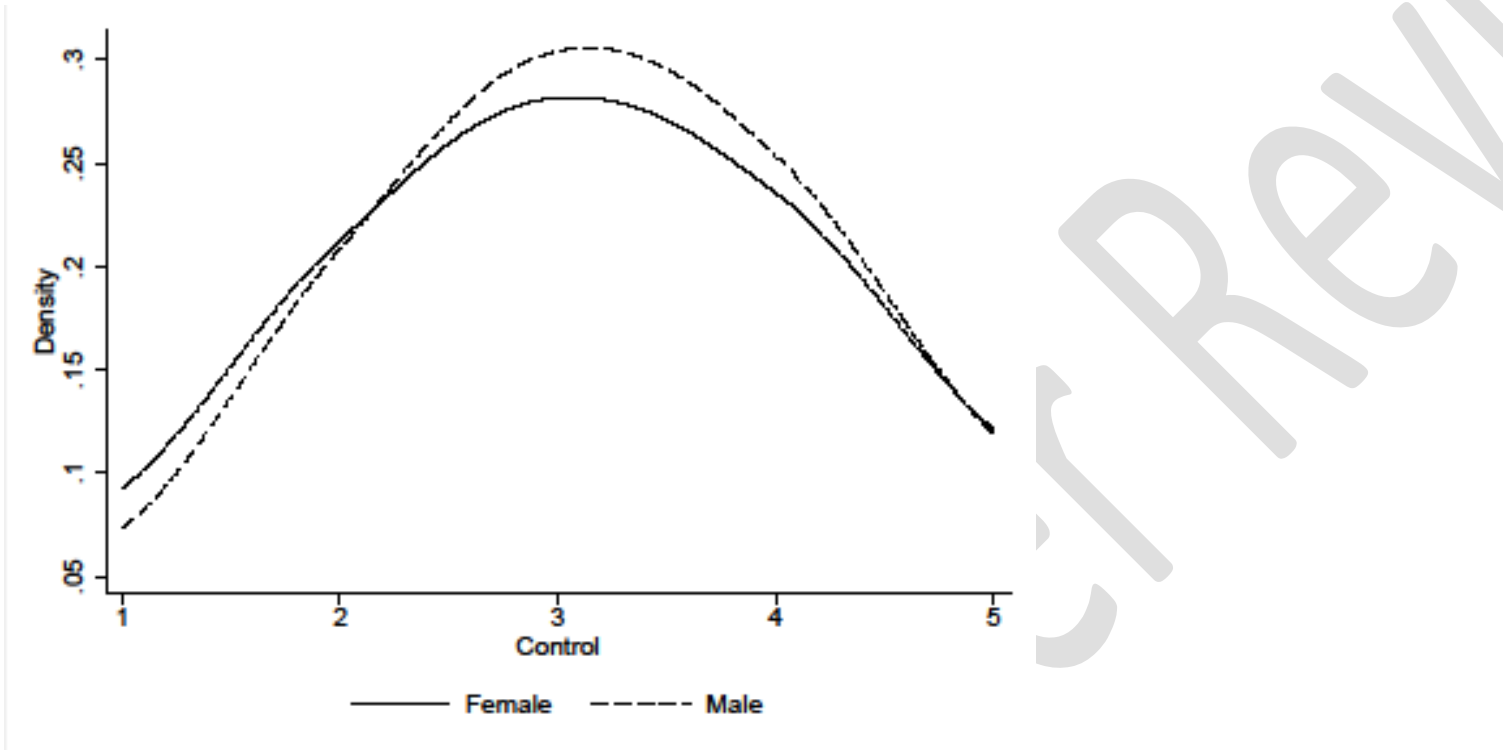

Notes: The density graph shows the difference in the distribution of the degree of control, conditioning on gender of the financial advisors 
Figure 3. Conditional Density Function: Recommended Portfolio.

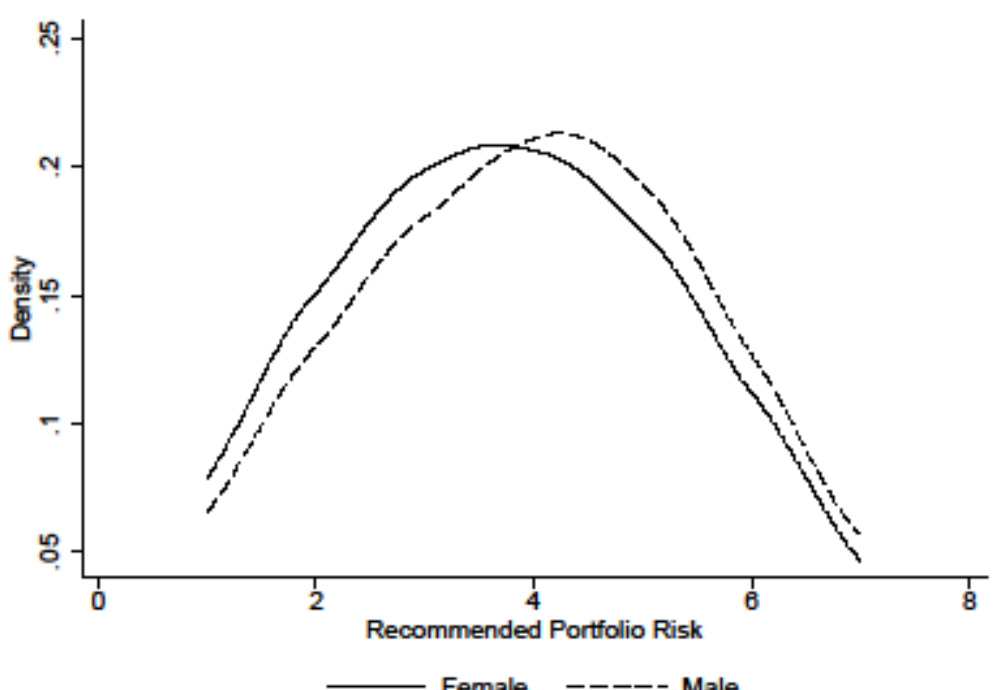

Notes: The density graph shows the difference in the distribution of the recommended portfolio, conditioning on gender of the financial advisors. 